\title{
DESCRIÇÃO QUALITATIVA DA CONCORDÂNCIA VERBAL: A ALTERNÂNCIA PRONOMINAL ENTRE NÓS E A GENTE
}

\section{QUALITATIVE DESCRIPTION OF VERBAL AGREEMENT: PRONOMINAL ALTERNANCE BETWEEN NÓS AND A GENTE}

\author{
João Miguel Lahoz Rinaldi*
}

Unesp/Ibilce

João Wilson Lima e Silva**

Unesp/Ibilce

Rafael Gardiolo***

Unesp/Ibilce

\section{Renata dos Santos Martins Alves ${ }^{* * * *}$ \\ Unesp/Ibilce}

\section{Vinícius Troncoso ${ }^{* * * * *}$}

Unesp/Ibilce

\section{Gustavo da Silva Andrade ${ }^{* * * * * *}$ \\ Unesp/Ibilce}

Resumo: Revisitando a literatura gramatical (CUNHA; CINTRA, 2001; PERINI, 2005; BECHARA, 2009; ROCHA LIMA, 2011), contraposta a outros estudos, como os de Souza (2017), de Tarallo (1985) e de Monteiro (2008), este artigo objetiva discutir a Alternância Pronominal (AP) entre nós e a gente, juntamente com a Concordância Verbal (CV), a fim de descrever o comportamento de um único falante, atingindo certo grau de homogeneidade linguística. Para tanto, selecionamos, por amostragem aleatória, um inquérito do banco de dados Iboruna (GONÇALVES, 2007). Identificamos uma preferência pelo uso do a gente em relação ao nós e ao sujeito oculto; no entanto, nas ocorrências do uso do pronome pessoal nós, há preferência do informante pelo tempo verbal em forma coloquial, pois se apresenta por pretérito perfeito.

Palavras-chave: Concordância Verbal. Sociolinguística. Português Falado. Iboruna. Nós/A gente.

\footnotetext{
${ }^{*}$ Graduando em Letras (Português/Italiano) pela Universidade Estadual Paulista (Unesp), Câmpus de São José do Rio Preto (Ibilce). E-mail: jomiguelar42@gmail.com.

** Graduando em Letras (Português/Inglês). E-mail: jwlima.2012@gmail.com.

*** Graduando em Letras (Português/Inglês). E-mail: gardiolocampos@outlook.com.

**** Graduanda em Letras (Português/Inglês). E-mail: renataalves.rp@hotmail.com.

***** Graduando em Letras (Português/Italiano). E-mail: viniciustroncoso97@gmail.com.

****** Doutorando em Estudos Linguísticos. E-mail: gustavo.s.andrade@unesp.br.
} 
Abstract: Revisiting the grammatical literature (CUNHA; CINTRA, 2001; ROCHA LIMA, 2011; BECHARA, 2009; PERINI, 2005), opposed to other studies, e.g. Souza (2017), Tarallo (1985) and Monteiro (2008), this article aims to present a description of alternation between verb agreement patterns between personal pronouns nós ('we') and a gente ('we'). For this purpose, we selected, by random sampling, an inquiry from the Iboruna database (GONÇALVES, 2007). We identified a preference for the use of a gente in relation to nós and to the elliptical subject; however, in the occurrences of the use of the personal pronoun nós, there is a preference by the informant for the verbal time in colloquial form, because it is presented as present perfect.

Keywords: Verb Agreement. Sociolinguistics. Spoken Portuguese. Iboruna. Nós/A gente.

\section{INTRODUÇÃO}

Parecer haver consenso quanto à definição da Concordância Verbal (de agora em diante, CV) nas gramáticas prescritivas do português. Rocha Lima (2011) define a CV como a relação, em número e em pessoa, desencadeada, em uma oração, pelo núcleo do sujeito no verbo. De acordo com Cunha e Cintra (2001), o fenômeno de CV caracteriza-se como a alternância do verbo para concordar com o sujeito em número e em pessoa.

No Português Brasileiro (doravante, PB), a variação no uso da CV parece estar diretamente relacionada à desigualdade social presente no país. Variantes utilizadas pelas classes mais abastadas tendem a ser consideradas como privilegiadas e, algumas vezes, prescritas como a "forma correta” em livros didáticos. Por sua vez, as variantes utilizadas pelas classes socialmente marginalizadas tendem a sofrer com o estigma da sociedade. Dessa forma, a compreensão das desigualdades sociais tem, como fator necessário, a análise linguística.

Monteiro (2008) divide as variantes em estigmatizadas e em não estigmatizadas. Estas são construções aceitas pela sociedade; aquelas, em sua maioria, não são aceitas socialmente, por estarem relacionadas a camadas mais marginalizadas e/ou excluídas.

Se um falante é um camponês ou mora numa favela, se é analfabeto ou de baixo nível de escolaridade, é lógico que sua maneira de falar não será a mesma que a das pessoas que se situam no ápice da pirâmide social. Em todos os níveis linguísticos se manifesta essa distância: na fonológica, no léxico, na sintaxe. Ele provavelmente usará formas como vrido, pranta, expilicar e musga ou construções do tipo nós veve, ele viu eu, eu se danei etc. E, com isso é mais discriminado ainda pela sociedade (MONTEIRO, 2008, p. 65).

No entanto, tais variantes não podem ser analisadas, desconsiderando-se seu contexto social. Isso porque muitas construções, tidas como estigmatizadas pela Gramática Normativa, não o são por seus falantes em seu núcleo familiar, por exemplo.

Este artigo apresenta uma análise qualitativa da CV, instanciada pela Alternância Pronominal (AP, de agora em diante) entre formas alternantes de primeira pessoa do plural (nós/a gente). É preciso destacar que, no que tange a esse fenômeno linguístico, é possível analisá-lo sob três perspectivas, quais sejam: (i) considerando-se, apenas, a CV; (ii) considerando-se, apenas, a AP; ou, ainda, (iii) considerando-se o entrecruzamento dessas duas variáveis. Neste trabalho, optamos por um recorte qualitativo da CV, considerando-se a AP como um fenômeno a priori 
e não controlado neste trabalho. Para tanto, utilizamos um único inquérito (o que possibilita analisar, efetivamente, os contextos de alternância) da Amostra Censo (daqui em diante, AC), compilada no Banco de Dados Iboruna (GONÇALVES, 2007), representativa do século XXI, o qual reúne amostras de fala espontânea do português falado no noroeste paulista.

O inquérito usado conta com apenas dezoito (18) ocorrências dos pronomes estudados, o que viabiliza certo grau de detalhamento, justificando o recorte referente à descrição qualitativa dos elementos. À guisa de conclusão, parecer haver uma preferência do uso de a gente em detrimento de nós e, no contexto de informalidade da Narrativa Recontada (NR), ${ }^{1}$ a forma nós vem demarcada por CV formada com o pretérito perfeito.

Expostos nossos objetivos e, brevemente, os resultados parciais, este trabalho organiza-se em quatro seções. Na primeira seção, apresentamos os pressupostos teóricos que embasam nossa discussão, além de problematizarmos a definição da CV entre as gramáticas descritivas e prescritivas (CUNHA; CINTRA, 2001; PERINI, 2005; BECHARA, 2009; ROCHA LIMA, 2011). A segunda seção pauta-se em uma explicação da CV à luz da teoria variacionista. Seguem-se, na terceira seção, os métodos utilizados e, na quarta seção, mostramos os resultados. Por fim, apresentamos nossas considerações e as referências utilizadas.

\section{PRESSUPOSTOS TEÓRICOS}

Para analisar a variação da CV entre nós e a gente, é preciso revisar a literatura, a fim de identificar os critérios suficientes e necessários para a construção de uma definição concisa e coerente da CV. Para Cunha e Cintra (2001), a concordância é explicada em termos de uma relação desencadeada.

Solidariedade entre o verbo e o sujeito, que ele faz viver no tempo, exterioriza-se na CONCORDÂNCIA, isto é, na variabilidade do verbo para conformar-se ao número e à pessoa do sujeito (CUNHA; CINTRA, 2001, p. 496).

Bechara (2009) coaduna com a definição de Cunha e Cintra (2001), expandindo-a para casos de CV em que se relaciona o predicativo na oração. Isto é, “[...] [a] concordância verbal [...] se verifica em número e pessoa entre o sujeito (e às vezes o predicativo) e o verbo da oração” (BECHARA, 2009, p. 441).

Perini (2005) problematiza as conceitualizações da CV nas gramáticas prescritivas. Entretanto, o próprio autor compreende a necessidade de escolha das gramáticas por conceitos cristalizados, a fim de um norteamento metodológico que possibilite extrair regras gerais de CV. Até mesmo a expansão do predicativo para orientação da CV é desconstruída, uma vez que as normas gramaticais não conseguem agrupar toda forma de CV no PB.

Já a solução proposta aqui entende a concordância como um sistema de filtros (independentemente motivados) que suprime certas estruturas por apresentarem má formação de algum tipo. É importante enfatizar que esses filtros nunca são

\footnotetext{
${ }^{1}$ A Narrativa Recontada é a reprodução de fato alegre ou triste ocorrido com outrem, sem envolvimento do informante (GONÇALVES, 2019, p. 287).
} 
específicos dos casos de concordância verbal, mas são necessários na gramática de qualquer maneira (PERINI, 2005, p. 192).

Nota-se que esse problema é facilmente observado nos traços de variedades com maior prestígio. No caso do vernáculo, a norma é ainda mais problemática.

Acontece que o “erro de concordância” não é uma decorrência direta do mecanismo da concordância, mas de outros fatores gramaticais — em outras palavras, o "erro de concordância” em si não existe. Trata-se, antes, da violação de certos filtros e restrições independentes do mecanismo da concordância (PERINI, 2005, p. 189).

Resumidamente, Cunha e Cintra (2001) e Bechara (2009) apontam as contradições entre os usos de vernáculo com a prescrição gramatical: indicam apenas como erro as variedades de CV do informante, enquanto Perini (2005) indica a problemática de apontar as variedades de CV como violações ou com erros sem a análise e sem a descrição das ocorrências.

Os gramáticos prescritivos supracitados refletem que a omissão do sujeito (atestada por sua repetição), por meio da concordância e do sujeito oculto, parece justificar a concordância como mecanismo de economia linguística e de coesão e de coerência textuais (cf. KOCH, 1990; 1996). Para Cunha e Cintra (2001, p. 496), a concordância evita repetição do sujeito, marcando-o por meio da flexão em número e em pessoa. Significa dizer que até mesmo normas prescritivas possuem suas intersecções com o vernáculo do informante. Portanto, é mister a necessidade de descrição de cada ocorrência a partir de regras prescritivas, seja para traçar problemáticas como até mesmo intersecções.

Para os gramáticos prescritivos, via de regra, se houver um único sujeito, “[...] o verbo concorda em número e pessoa com o seu sujeito, venha ele claro ou subentendido” (CUNHA; CINTRA, 2001, p. 497). Quando a oração tem dois ou mais sujeitos, os autores apresentam variabilidade da regra.

O verbo que tem mais de um sujeito (SUJEITO COMPOSTO) vai para o plural e, quanto à pessoa, irá:

a. para a $1^{\text {a }}$ pessoa do plural, se entre os sujeitos figurar uma da $1^{\mathrm{a}}$ pessoa $[. .$.

b. $\quad$ para a $2^{\mathrm{a}}$ pessoa do plural, se, não existindo sujeito da $1^{\mathrm{a}}$ pessoa, houver um da $2^{\mathrm{a}}[\ldots]$

c. $\quad$ para a $3^{\mathrm{a}}$ pessoa do plural, se os sujeitos forem da $3^{\mathrm{a}}$ pessoa. (CUNHA; CINTRA, 2001, p. 497-498).

Quanto à utilização de nós, como pronome prototípico de primeira pessoa do plural, os autores apontam tratar-se de um subtipo de pronome pessoal, caracterizado por denotar aquele que fala (cf. BENVENISTE, 1976), além da noção de pluralidade, que pode incluir ou não o falante (CUNHA; CINTRA, 2001, p. 276). Os autores concluem que o uso do pronome nós desencadeia relações de concordância. "Dizemos que um verbo está no singular quando ele se refere a uma só pessoa ou coisa e, no plural, quando tem por sujeito mais de uma pessoa ou coisa” (CUNHA; CINTRA, 2001, p. 380).

Quanto à concordância com a pessoa, os autores apontam ainda que o verbo possui três pessoas, diretamente relacionadas com a pessoa gramatical que atua como seu sujeito. “A 
primeira pessoa é aquela que fala e corresponde aos pronomes pessoais eu (singular) e nós (plural)” (CUNHA; CINTRA, 2001, p. 380).

Quanto a a gente, Cunha e Cintra (2001, p. 214) identificam seu uso como sendo coloquial, i.e., “[...] emprega-se a gente por nós, e, também, por eu”. Significa dizer que a gente é utilizado como forma de primeira do plural, mesmo que, quanto à concordância, difira de nós: “[...] o verbo deve ficar sempre na $3^{\mathrm{a}}$ pessoa do singular” (ibid).

\section{TEORIA DA VARIAÇÃO}

A concordância ideológica desencadeada entre a gente e o sintagma verbal, i.e., quando o falante constrói frases como “a gente vamos”, acontece devido à ideia de pluralidade que o pronome pessoal carrega e como ele faz a concordância verbal (apenas com verbos na $3^{\mathrm{a}}$ pessoa do singular). O inverso ocorre com o pronome pessoal nós, que, apesar de carregar a pluralidade, faz concordância verbal com verbos na $1^{\text {a }}$ do plural, como indicou Rubio (2011) em sua análise de PB e Português Europeu (PE).

Nas variedades do PB e mesmo do português europeu (PE, daqui em diante), a inclusão de novas formas de menção às pessoas do discurso reelaborou o quadro pronominal e de $\mathrm{CV}$, o que ocasionou como resultado a falta de correspondência entre mesma pessoa e desinência verbal (RUBIO, 2011, p. 2).

Falantes dentro do extrato social marginalizado tendem a fazer concordância ideológica, enquanto aqueles que têm maior nível de instrução utilizam formas mais próximas daquelas previstas pela gramática prescritiva, como orienta Pacheco (2018).

Posteriormente houve uma mudança linguística em que a gente transformou-se em pronome de primeira pessoa do plural (“tolerável”), ainda não totalmente gramaticalizado, principalmente se levarmos em consideração que a expressão $a$ gente podemos é estratificada socialmente no português brasileiro e, portanto, não é um traço gradual das variedades linguísticas do Brasil. Esse caso é mais estigmatizado e menos recorrente no português brasileiro do que no português europeu (“proscrito”) (PACHECO, 2018, p. 232).

A perspectiva variacionista prevê, entretanto, a heterogeneidade na língua, uma vez que, como pontua Tarallo (1985), considera o “caos” linguístico como um objeto de estudo e de análise, o qual surge do embate entre variantes linguísticas. Dessa forma, a noção de que todos os falantes interagem de forma igual cai por terra. Labov (2008 [1972]) afirma que a língua é heterogênea e diversificada; posicionamento esse que é retomado por Tarallo (1985) e, também, por Monteiro (2008), ao afirmar que “[...] uma das tarefas da sociolinguística é descrever as línguas em sua diversidade funcional e social” (MONTEIRO, 2008, p. 39).

Segundo Labov (1972), o pesquisador na área de sociolinguística analisa o vernáculo, sendo descrito como "[...] o estilo em que é mínima a atenção voltada para o discurso, isto é, a fala mais espontânea possível” (MONTEIRO, 2008, p. 49).

Portanto, o presente artigo, sendo uma investigação no campo da sociolinguística, “[...] deverá partir de registros de fala” (MONTEIRO, 2008, p. 85), i.e., analisamos as ocorrências 
retiradas de um inquérito produzido a partir da narrativa de um informante sobre as suas experiências pessoais.

Quanto ao presente estudo, a CV parece ser instanciada no PB a partir da AP entre as formas nós e a gente; as quais estão em contexto de variação, correspondendo a variantes linguísticas que são "as formas alternantes, que expressam a mesma coisa num mesmo contexto" (MONTEIRO, 2008, p. 59). De modo que, ao invés de considerar como desvio aquilo que foge do que dita a Gramática Normativa, tomamos como base a afirmação de que "[...] a cada variante correspondem certos contextos que a favorecem” (TARALLO, 1985, p. 36). Esses contextos podem ser linguísticos ou extralinguísticos, como "[...] formalidade vs. informalidade do discurso, o nível socioeconômico do falante, sua escolaridade, faixa etária e sexo” (TARALLO, 1985, p. 46), dentre outros.

Na próxima seção, à luz dessas breves considerações, indicamos os métodos utilizados neste trabalho e que seguem uma análise qualitativa da ocorrência da concordância verbal.

\section{MÉTODOS}

Para elaboração do artigo, utilizamos o banco de dados Iboruna, acerca do português falado no noroeste paulista, resultado do projeto Amostra Linguística do Interior Paulista (ALIP), financiado pela FAPESP e desenvolvido pela Universidade Estadual Paulista (Unesp), câmpus de São José do Rio Preto, sob supervisão do Prof. Dr. Sebastião Carlos Leite Gonçalves (Unesp/ Ibilce). Esse banco de dados é formado pela AC, em que cada entrevista corresponde a cinco arquivos sonoros, diário de campo, ficha social do entrevistado e transcrição ortográfica da entrevista. Também é formado pela Amostra de Interação Dialógica (AI), coletada secretamente em situação de interação social, com um arquivo de áudio correspondente, diário de campo, ficha com dados do entrevistado e transcrição ortográfica da conversa.

A análise foi produzida a partir de uma AC, sendo a escolha metodológica do uso de dados do Iboruna justificada pelo conflito entre as variações nós e a gente no contexto do português falado no noroeste paulista. São estabelecidas, no artigo, as variantes-padrão (presença de concordância), a partir dos estudos prescritivos de Cunha e Cintra (2001) e, ainda, Rocha Lima (2011), para determinar o que seria julgado como "correto" por classes abastadas e quase sempre se apresenta como conservadora, aquilo que tenta esbarrar a novidade, manter formas cristalizadas no contexto da comunidade e, ainda, tende a possuir o maior prestígio social entre os falantes. Já as variantes não-padrão retiradas do vernáculo utilizado pelo entrevistado são as inovadoras, com menor prestígio social. No substrato da pesquisa, a concordância verbal é identificada a partir da AP entre nós e a gente e da relação tempo-verbal no discurso do informante.

Tarallo (1985) afirma que, em fenômenos específicos das variações, em determinadas comunidades, pode não ser verificada uma clara e cristalizada dicotomia de inovação estigmatizada e de conservação prestigiosa, i.e., os dados coletados sobrepõem-se às hipóteses do pesquisador.

Realizamos uma investigação qualitativa, a partir de um inquérito do corpus Iboruna. Tal análise, mesmo que compreenda apenas um único informante, não prejudica a qualidade da descrição, pois atingimos um certo nível de homogeneidade. Possibilita-nos, também, considerar o efetivo contexto social-econômico-geográfico. 
Dentro do escopo de coletas de dados, vale ressaltar a problemática no gênero entrevista: o paradoxo do pesquisador (cf. LABOV, 1976). Os dados podem ser comprometidos a partir da interferência do entrevistador para com os entrevistados, "ora estando presente o investigador, o falante se expressa com algum grau de formalidade e, por conseguinte, sua fala não será espontânea” (MONTEIRO, 2008, p. 33). Uma forma possível descrita por Tarallo (1985) para tentar amenizar essa problemática é propor coleta a partir de narrativas de experiência pessoal, posto que o informante se preocupa em manter entretido o interlocutor e, assim, é menos cuidadoso ao utilizar as variantes com maior prestígio, aproximando-se de seu vernáculo.

A observância do paradoxo do observador foi o respaldo determinante para a escolha metodológica na utilização dos dados do Iboruna, pois a forma que as entrevistas são conduzidas, a partir de perguntas pessoais do entrevistador para com o informante, condiz com as decisões de coleta de dados e análise presente neste artigo.

Como já mencionado, analisamos um inquérito da AC. A seleção foi motivada por uma amostragem aleatória: utilizamos o software Bioestat para selecionarmos um inquérito para a análise e para as análises estatísticas. O informante é um homem, na faixa etária entre 16-25 anos, originário de São José do Rio Preto, cuja escolaridade vai até o primeiro ciclo do ensino fundamental e de renda familiar de até dois salários mínimos.

Através do estudo dos áudios e da transcrição da entrevista, ambos disponíveis no site do Iboruna, analisamos a CV, considerando, também, a AP entre nós e a gente. Sendo assim, as ocorrências no inquérito foram levantadas e quantificadas. Mesmo em se tratando de um trabalho qualitativo, a análise quantitativa é possível e contribui para os estudos da CV e da AP no PB: permite comparar dados de uma amostra como um todo (a AC do Iboruna) com dados de um único falante.

Os gráficos foram confeccionados para instrumentalizar as ocorrências, e não para aferir o uso de nós e a gente em contexto social-geográfico-econômico do falante. O artigo é resultado de análise de dados de um único inquérito, sendo impossível configurar qualquer tipo de resultado conclusivo sobre a disputa das variantes. Contudo, os gráficos e a instrumentalização desses dados auxiliam e corroboram para futuros artigos com intenção de determinar os usos das variantes no contexto extraído pelo Iboruna.

Nossas análises consideram, em certa medida, a noção de erro expressa pela gramática tradicional. Camacho (1988) afirma, ao discutir a proposta de estudo da variação linguística, que existem duas noções de "erro" dentro do ensino de Língua Portuguesa: a primeira decorre de uma noção de norma/gramática como um conjunto de regras que devem ser seguidas, aos moldes de uma norma jurídica; "erro" seria, pois, tudo aquilo que foge a essas regras. A segunda definição, por sua vez, assume a norma/gramática como um conjunto de regras que são, efetivamente, usadas; “erro”, portanto, seria uma construção que não comunica.

Posto isso, assumimos as categorias da Gramática Normativa para discutirmos esses contextos de inadequação da concordância. Mesmo porque a noção de "erro" inexiste, uma vez que todas as formas possíveis de AP e de variação da CV são justificáveis e comunicativamente bem formuladas. Essa justaposição entre categorias e noções da Gramática Normativa e o uso efetivo pelo informante não se configura como uma tentativa de adequação ou de justificação do preconceito linguístico: inexiste, então, a noção de "erro". Tal justificativa é necessária para que, em um movimento discursivo, não incorramos em utilizar categorias e/ou termos 
da Gramática Normativa/Prescritiva e mantenhamos um simulacro discursivo de denominar a variação como "erro".

As variantes, a priori, podem parecer caóticas por conta do seu contexto de disputa, como Tarallo (1985) define, a língua pode ser concebida como palco belicoso das variantes; entretanto, o próprio autor alega que essa disputa pode ser catalogada e compreendida.

As gramáticas prescritivas utilizadas foram Cunha e Cintra (2001), Rocha Lima (2011) e Bechara (2009), por seu destaque nacional como prumo para determinar quais seriam as formas esperadas na construção dentro dos parâmetros da dita norma culta. Além disso, como forma de problematização, foi usada uma gramática descritiva, que possui o mesmo renome e importância dos outros autores, elaborada por Perini (2005). Dessa forma, nossa análise, mesmo que se valha de conceitos da Gramática Normativa, não assume como verdadeiro seu julgamento ou sua avaliação das escolhas de uso do informante por análise crítica de Perini (2005) sobre as gramáticas descritivas e, ainda, o artigo seguiu o norteamento dos pressupostos teóricos da Teoria da Variação, i.e., não há nenhum tipo de aferimento sobre as decisões, apenas descrições e demonstrações qualitativas.

Os casos discriminados foram descritos detalhadamente, afinal "é imprescindível que, em primeiro lugar, apresente, defina e caracterize detalhadamente cada uma dessas concorrentes” (TARALLO, 1985, p. 33). O artigo parte da definição de linguagem como palco de conflito dos usos, entretanto com um objeto, método e corpus definido, sendo assim, a descrição do inquérito é uma instrumentalização dos dados que foi possível extrair a partir das ocorrências observadas no inquérito do Iboruna.

As descrições detalhadas são para catalogar as variantes em estado de disputa dentro da fala do informante, como próprio Tarallo (1985) retoma a partir do descrito por Labov como uma condição natural no campo da fala, tanto em um campo micro (indivíduo) como macro (comunidade).

Tal como proposto por Labov, a concepção e o alcance do modelo sociolinguístico são a um só tempo sincrônicos e diacrônicos: tanto a variação (situação linguística em vários momentos sincrônicos, avaliados longitudinalmente; diacronia) (TARALLO, 1985, p. 35).

A opção de descrição das ocorrências é para delimitar e compreender a forma que se relaciona essa disputa no discurso do informante, pois ela pode ser facilmente compreendida como um caos linguístico. Apesar disso, Tarallo (1985) afirma ser possível a descrição das ocorrências, porque o caos é apenas aparente. A atividade de descrição é para facilitar a instrumentalização de dados em pesquisa e possui o objetivo de mensurar como relacionam as variantes dentro da fala do informante. 


\section{ANÁLISE QUALITATIVA}

No inquérito em análise, identificamos 18 (dezoito) ocorrências do fenômeno em análise, das quais 8 (oito) referem-se ao uso de nós e 10 (dez) de a gente, como exemplificado no Gráfico 1.

Gráfico 1: Uso de nós e a gente pelo informante no inquérito analisado.

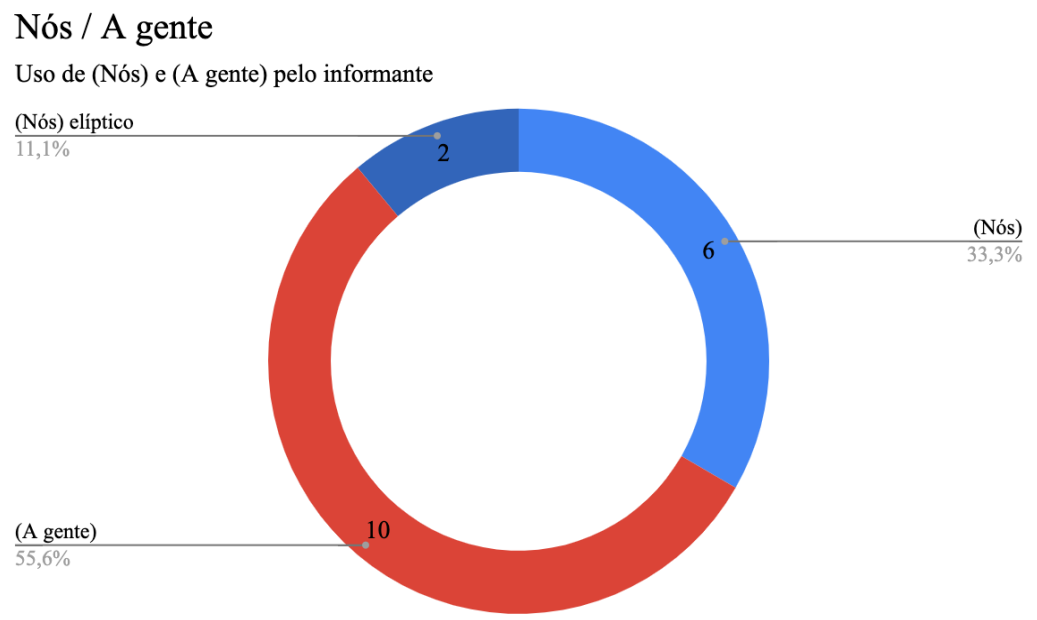

Fonte: elaborado pelos autores.

Agrupamos, para a análise, ocorrências com sujeito pronominal expresso ou que possa ser resgatado, como exemplificado em (1) e (2).

(1) descemo(s) no bar pa to/ jogá(r) um bilhar (AC-031, 2007, p. 2)

(2) escutamo(s) um barulho numa:: casa vizinha do lado (AC-031, 2007, p. 2)

A oração (1) faz parte da sessão NR do relato do informante, quando ele reconta um conflito que houve entre dois amigos, no qual um deles estava roubando fios de cobre da casa do outro. No exemplo (1), o informante refaz parte de sua frase, representado pela barra (/), quando chega no verbo jogar, o falante suprime o morfema [r] final. O exemplo (2) surge na continuação da NR, na qual o informante faz um prolongamento da vogal, representado pelos dois pontos repetidos (::), e depois continua a sua fala. Nos casos (1) e (2), o falante faz uso da desinência de $1^{a}$ pessoa do plural, porém, suprime o morfema [s] final por subentender que tal desinência verbal já carrega sentido de plural sem o morfema [s].

O grupo de fatores explicitude do sujeito apresentou relevante atuação na CV com a gente, demonstrando que contextos de sujeito explícito favorecem o emprego da variante verbos em $3 P S$ e contextos de sujeito oculto ou desinencial, favorecem o emprego de verbos em 1PP, justificado pela necessidade de reiteração da referência à $1 \mathrm{PP}$ do discurso, nesses casos, presente somente na desinência verbal. Dessa forma, independentemente da forma pronominal presente em oração anterior (nós ou a gente), há sempre a tendência ao uso de verbos em 1PP nos contextos de sujeito oculto ou desinencial (RÚBIO, 2014, p. 174, grifos no original). 
No inquérito estudado, o informante tende a fazer concordância verbal entre nós e a gente nos seguintes tempos verbais: PST.MPFV, PST.IPFV, PST.PFV e PRES. ${ }^{2}$

Gráfico 2: Tempos verbais em que ocorre CV padrão entre nós e a gente.

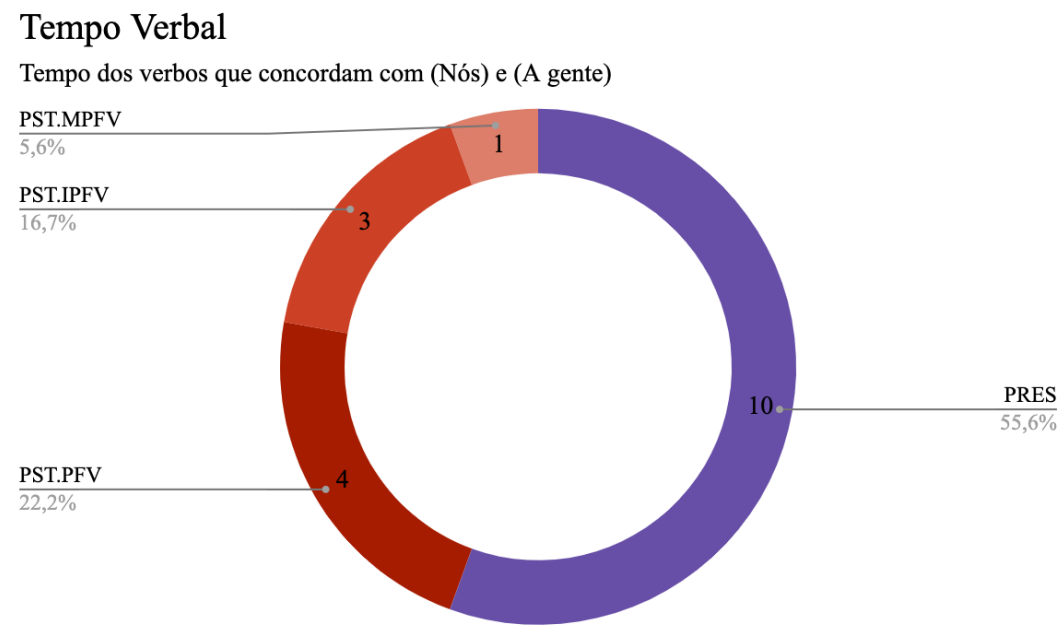

Fonte: elaborado pelos autores.

Identificamos que o informante tende a concordar verbalmente, no PRES, com a gente, sendo que peso de ocorrências é 0.7 e, no caso do pronome pessoal nós, o peso é 0.3. Para o PST.IPFV, as ocorrências identificadas foram de peso 0.1 para nós e 0.2 para a gente. A concordância em PST.MPFV foi feita apenas com a gente, resultando em peso 0.1. Quando o tempo é PST.PFV, não foram identificadas ocorrências com a gente, no entanto, foi observado que as ocorrências de concordância de nós ocorrem conjuntamente com os dois casos de sujeito oculto, como na NR em “descemo(s) no bar” e “escutamo(s) um barulho”, resultando em peso 0.2. Tais ocorrências - uso do pronome pessoal nós com o PST.PFV - indicam que mesmo o falante usando o pronome pessoal padrão, está relacionado com um contexto de informalidade devido ao tempo verbal, que está em sua forma simples, como demonstra Barbosa (2012).

Quanto ao PPS [...], verificamos que, tanto no PB quanto no PP, o número de ocorrências foi próximo. Entretanto, podemos observar que houve maior frequência de PPS nos textos [-] formais: no PP encontramos 382 (68\%) formas simples, e no PB, 398 (73\%) (BARBOSA, 2012, p. 191).

Ainda de acordo com a autora, isso ocorre "[...] porque os textos [-] formais de nosso corpus são compostos por cartas informais e, em sua maioria, contêm diversos trechos com narrativas de fatos passados (perfectivos) [...]” (BARBOSA, 2012, p. 191). Indo ao encontro da tendência identificada por Barbosa (2012), identificamos, no inquérito em análise, que os casos de concordância no PST.PFV com sujeito oculto ocorreram na seção em que o entrevistador pede para o informante recontar um fato ocorrido com alguma pessoa que ele conhece (NR).

\footnotetext{
${ }^{2}$ Neste trabalho, utilizamos as seguintes siglas para os tempos verbais: PST.MPFV (pretérito mais que perfeito), PST.IPFV (pretérito imperfeito do indicativo), PST.PFV (pretérito perfeito do indicativo) e PRES (presente do indicativo).
} 
Gráfico 3: Concordância verbal entre nós e a gente relacionada com os tempos verbais.

\section{Tempo Verbal}

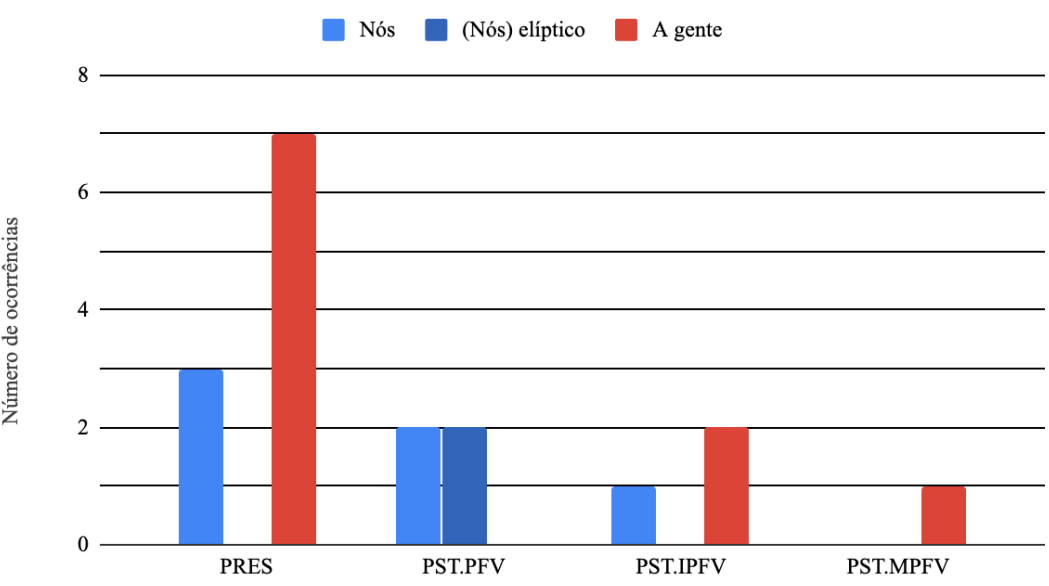

Fonte: elaborado pelos autores.

Em relação à transitividade verbal de nós, sujeito oculto e a gente, o informante tende a usar nós com verbos transitivos diretos, resultando em peso 0.4, sendo que, em apenas um desses casos, o informante faz concordância verbal com o sujeito ("escutamo(s) um barulho"). Nesse único caso, o sujeito é elíptico, por isso o peso resultante de nós elíptico é 0.1. Em relação aos verbos transitivos indiretos, o único caso de nós coincide com o caso de sujeito oculto ("descemo(s) no bar"), resultando em peso 0.1. Quanto ao a gente, o peso é 0.3, sendo que o informante faz concordância em todos os casos (“a gente tava lá fora”, "a gente tinha costumado" e "a gente fica ali”). Em relação aos verbos intransitivos, o peso para o pronome nós e a gente coincide, sendo 0.1 nos casos "nós vai...” e "a gente mo/ é a casa que a gente tá moran $(d) o "$, respectivamente.

Gráfico 4: Transitividade verbal entre nós e a gente.

\section{Transitividade Verbal}

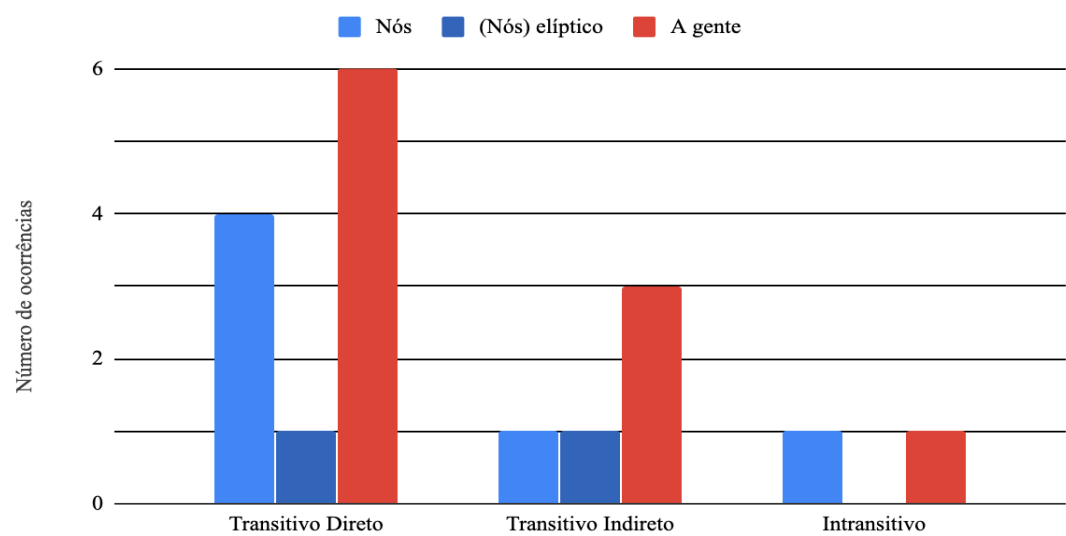

Fonte: elaborado pelos autores. 
Por fim, foi obtido, como resultado, o peso 0.1 para a concordância verbal do pronome pessoal nós, porém, nos casos de nós elíptico, o peso foi 0.2 para o uso padrão da concordância. Enquanto isso, o peso para a gente foi categórico. Os únicos casos não-padrão identificados foram relacionados ao pronome nós, resultando em peso 0.5 .

Gráfico 5: Gráfico comparativo da concordância verbal do uso de nós, sujeito oculto e a gente.

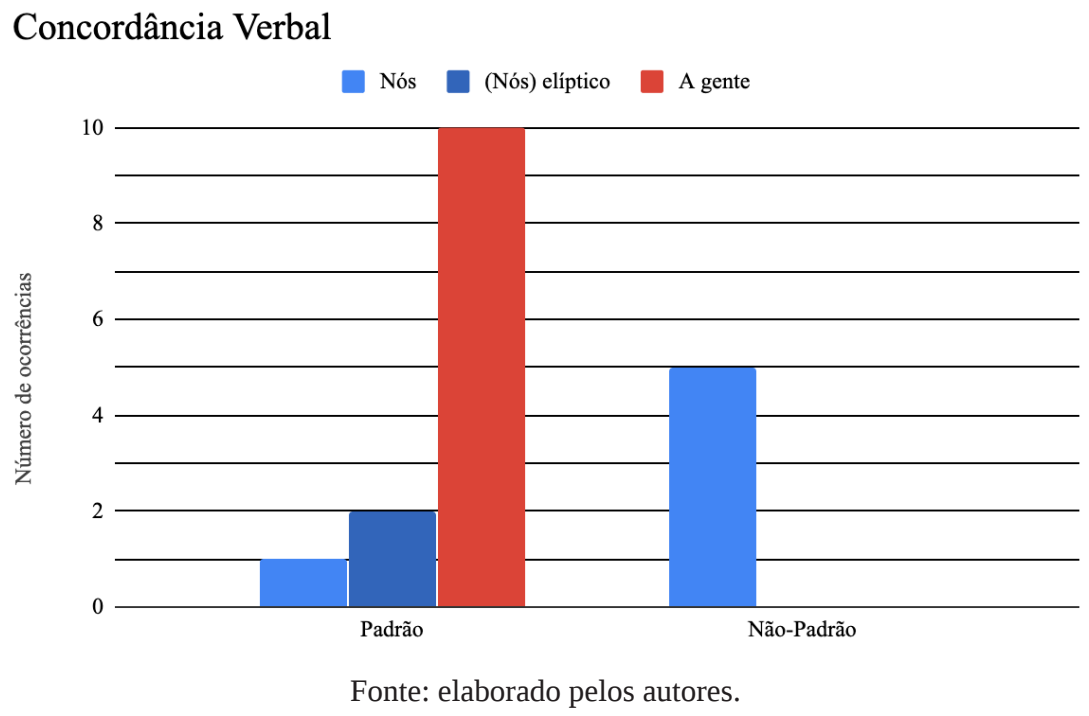

\section{À GUISA DE CONCLUSÃO}

Em decorrência da AP entre as formas nós e a gente, foi possível atestar 8 (oito) ocorrências de nós e 10 (dez) ocorrências de a gente, totalizando 18 (dezoito) ocorrências de primeira pessoa do plural. A partir da análise qualitativa das ocorrências supracitadas, identificamos uma relação entre o sujeito oculto (especialmente, com formas sequenciais de nós) e o verbo em PST. PFV, atestada pelo levantamento de dados descritos no Gráfico 3. Dessa forma, comprovamos nossa hipótese inicial da sobreposição do uso de a gente em relação a nós e, ainda, a utilização majoritária do uso do pronome nós em conjunto com verbos no PST.PFV.

Neste trabalho, analisamos de forma qualitativa a CV. Identificamos, observando a partir da literatura sobre o tema, haver um aparente descompasso quando se observam dados gerais e dados individuais (o que nos levaria a pensar na possibilidade de haver outros parâmetros, e.g., a relação direta entre o falante e a situação de entrevista, que se dilui em uma análise puramente quantitativa). Contudo, há, ainda, certo grau de proximidade, no que diz respeito às preferências pelo uso de a gente e de certas formas verbais em detrimento de outras.

Vale ressaltar que, apesar da inviabilização de uma análise detalhada, por conta do pequeno número de ocorrências, esperamos que a descrição dos dados possa auxiliar futuras pesquisas na área, além de ressaltar a diferença nas definições de CV entre as gramáticas normativas e descritivas. 


\section{REFERÊNCIAS}

BARBOSA, J. B. O pretérito perfeito no Português do Brasil e no Português de Portugal Contemporâneo. Todas as Letras, São Paulo, v. 14, n. 1, p. 176-194, 2012.

BECHARA, E. Moderna Gramática Portuguesa. Rio de Janeiro: Nova Fronteira, 2009.

BENVENISTE, E. Problemas de linguística geral. São Paulo: Universidade de São Paulo, 1976.

CAMACHO, R. G. A variação lingüística. In: SÃO PAULO. Subsídios à proposta curricular de língua portuguesa para $01^{0}$ e $2^{\circ}$ graus. São Paulo: SE/CENP, 1988, v. 3.

CUNHA, C.; CINTRA, L. Nova gramática do português contemporâneo. Rio de Janeiro: Nova Fronteira, 2001.

GONÇALVES, S. Banco de dados Iboruna. 2007. Disponível em http://www.iboruna.ibilce. unesp.br. Acesso em 12 jun. 2019.

GONÇALVES, S. C. L. Projeto ALIP (Amostra Linguística do Interior Paulista) e banco de dados Iboruna: 10 anos de contribuição com a descrição do português brasileiro. Revista Estudos Linguísticos, Araraquara, v. 48, n. 1, p. 276-297, abr. 2019.

KOCH, I. G. V. A coerência textual. São Paulo: Contexto, 1990.

KOCH, I. G. V. A coesão textual. São Paulo: Contexto, 1996.

LABOV, W, Sociolinguistique. Paris: Minuit, 1976.

LABOV, W. Padrões sociolinguísticos. Tradução de Marcos Bagno, Maria Marta Pereira Scherre e Caroline Rodrigues Cardoso. São Paulo: Parábola, 2008 [1972].

MONTEIRO, J. Para compreender Labov. Rio de Janeiro: Vozes, 2008.

PACHECO, C. A diacronia e a sincronia dos pronomes de primeira pessoa do plural Nós e A Gente no português brasileiro e no português uruguaio. Revista de Estudos da Linguagem, Belo Horizonte, v. 26, p. 221-253, 2018.

PERINI, M. Gramática descritiva do português. São Paulo: Ática, 2005.

ROCHA LIMA, C. H. Gramática normativa da língua portuguesa. Rio de Janeiro: José Olympio, 2011.

RUBIO, C. Variação na concordância verbal com “a gente” no Português Europeu. Fórum Linguístico, Florianópolis, v. 11, p. 164-177, 2011.

SOUZA, C. Gramática discursivo-Funcional, gramaticalização e modalização. Revista de Estudos da Linguagem, Belo Horizonte, v. 25, n. 4, p. 2095-2126, 2017.

TARALLO, F. A pesquisa sociolinguística. São Paulo: Ática, 1985.

Recebido em: abr. 2020.

Aceito em: maio 2020. 